\title{
Establishing Learner Autonomy in China's Universities through Achievement Presentation
}

\author{
Haiyan Liu \\ School of Foreign Languages, University of Jinan, Jinan 25002, China
}

\author{
Wenqian Qi \\ School of Foreign Languages, Shandong University of Finance and Economics, Jinan 250014, China
}

\begin{abstract}
Learner's role in learning a foreign language has been paid more and more attention in the recent years and learner autonomy is widely recognized as an educational goal. How to integrate teaching with developing learner autonomy has become a hot topic in the educational reform. However, few researches have been made in China's specific class context. The extension learning achievement presentation (ELAP) activity conducted in two of China's universities is such an exploratory practice. Based on the theory of learner autonomy and the characteristics of university students, the ELAP is designed to make an integration of students' learning both in and out class so as to promote the simultaneous development of autonomous learning and language use abilities. The combination of classroom teaching with students' out class learning enables the foreign language learning to become a process of learner autonomy development. In the process of sharing each other's achievements, the students deepen their understanding of the knowledge learned and widen their horizon. The result of quantitative and qualitative data analysis reveals that the ELAP has greatly stimulated the students' enthusiasm in learning. They have undertaken reflective learning, made a better understanding of their learning methods and process, and raised their autonomous learning awareness and ability. And the teachers' orientation in helping shift the students' learning concept and methods has been proved to be the major affecting factor to success or failure of the ELAP and the cultivation of students' autonomous learning ability.
\end{abstract}

Index Terms - learner autonomy, achievement presentation, learning concept, teacher orientation

\section{INTRODUCTION}

Ever since H. Holec (1981) initiated the term "learner autonomy", the concept has long been a hot research topic and generally recognized as an educational goal (e.g. Dam, 1995; Dickinson, 1995; Little, 1991, 2002; Benson, 2001; He, 2003; Lamb \& Reinders, 2007). In the field of second and foreign language teaching and learning, learner autonomy has also been a buzz word, especially when concerning lifelong learning skills. Helping students become more autonomous in their learning has become one of the even more prominent themes of language teaching (Benson, 2001, p1). Language teaching is considered by many people as language learning, which has brought about a shift of center from teacher to learner, and more focus on the production of autonomous individuals who are capable of training themselves to meet changing economic needs and circumstances (Benson, 2000, p 111).

In China, English as a foreign language has been made a compulsory subject for about $90 \%$ of the middle school students since 1978 and for .almost all the non-English majors in colleges and universities. With many educational deficiencies found, reform was launched nationwide in the last decade of the $20^{\text {th }}$ century, and the cultivation of learner autonomy has been established as one of the ultimate goals in English education ever since. However, how to promote learner autonomy in China's existing educational environment remains a challenge. Although the teaching of English as a foreign language (TEFL) is in reform, it seems to fall far from meeting the needs of China's rapid development and learners' long-term demands. There have been widespread and sharp criticism of China's foreign language education such as "dumb English", "input more and yield less", "high marks and low ability". Students are used to following teachers' instructions in learning, seldom considering what they should do. Constant cries for learning reform and creativity come from experts and scholars (e.g. Liu, 2004). Cultivating students' ability to learn becomes more urgent with the development of information age and globalization. The development of learner autonomy, or learners' ability to take control over their own learning (Holec, 1981) is a way in which we may make links with learners at a more individualized level, and to connect classroom learning with out-class learning activities. It is significant in theory, pedagogy and methodology in Chinese learning context since learner autonomy is traditionally regarded in the western world as culturally biased and not fit for the eastern culture like China's.

This research, through the use of both quantitative and qualitative data at the different stages of students, is among the limited longitudinal studies in this field in China, covering two years and a half, not including the years of pilot study, As part of the teaching project numbered JZ0805, it is conducted with a framework of teacher's course orientation, students' out-class project-based extension learning, and achievement presentation in class followed by discussion and evaluation, attempting to explore a path to fostering students' autonomous learning ability and language 
proficiency simultaneously according to the TEFL in the Chinese context.

\section{RELATED THEORETICAL BASIS FOR THE RESEARCH}

It is extremely important for teachers to know something about the development of learner autonomy and the principal factors concerned since autonomy is recognized as multidimensional and takes different forms according to the person, the setting, and multiple contextual and micro-contextual factors.

\section{A. Learning Process}

In general, the complex learning process was not adequately described until the idea of education has moved from man as "product of society" to man as "producer of society" (Janne, 1977 cited in Holec, 1981, p1). Cognitive psychologists suggest that leaning is more effective if the learner integrates knowledge within a personal framework. Constructivists claim that knowledge is built by the learner, not given by the teacher and learning is a process in which learners construct their understanding on the basis of their personal experiences. They recognize that "if learning is a matter of the construction of knowledge, effective learners must be cognitively capable of performing actions that enable them to take control of their learning (Benson, 2005, p40), which is a very important contribution to the theory of autonomy in language learning. Humanistic psychologists stress affective aspects of learning and recognize the importance of providing learners with a learning environment, which has made a great influence on both the theory and practice of learner autonomy. All these researches have led to new definitions of both the learner's and the teacher's roles - the learner as an active participant in the learning, and the teacher as a facilitator and mediator helping learners to find ways of moving into their next level of understanding (Fruerstein, 1981; Vygotsky, 1962, cited in William \& Burden, 2006, p 67-68). A model proposed by van Esch and St. John (2003) states that learning process consists of 4 stages. The first stage engagement is a condition showing a learner's willingness and ability to learn. The second one exposure means a learner's contact with new knowledge and experience when his learning environments extend to domains beyond his previous knowledge or experience. The third one integration is a stage of cognitive digestion of new experiences and perceptions, and construction of new knowledge and conceptual systems on the basis of their prior knowledge and strategies. This is a process leading to a new synthesis of knowledge, deeper understanding and better performance. The fourth stage transference is the learner's free application of knowledge and skills to a wider range and/or varied areas of activities for different purposes in changing learning environments. All the four stages are interdependent with each other and learning takes place only when one passes through all these stages.

\section{B. Definitions of Learner Autonomy and Its Promotion}

Autonomy is commonly considered by its advocators as a precondition for effective learning. An autonomous learner is not only a successful language learner, but also a responsible and critical member of his communities. Nunan (1997) points out that some degree of autonomy is essential if a learner is to become effective language user, and autonomy can be fostered regardless of a learner's personality. Researchers who have tried to give definitions to learner autonomy (e.g. Dam, 1994; Wenden, 1991) all are consistent with Holec's (1981) view. As the initiator of the concept autonomy, Holec (1981) puts emphasis on the learner's reality, responsibility, motivation, self-evaluation, etc.. He has proposed one of the most widely adopted definitions in the literature, saying that autonomy is "the ability to take charge of one's own learning". An autonomous learner holds the responsibility for all decisions concerning aspects of learning, general or specific, such as objectives, contents and progressions, methods and techniques to be used, monitoring the procedure of acquisition properly speaking (rhythm, time, place, etc.), evaluating what has been acquired (Holec, 1981, p3). This interpretation provides the theoretical foundations for understanding and fostering autonomous behavior. Actually the wording "properly speaking" has already included the so-called social dimension that Dam (1994) has added and Little's similar definition such as "flexibly, taking account of the special requirements of particular circumstances". since if one can speak properly, he must at least have mastered the basic social communication strategies and techniques.

Agreement has been reached on the necessity of helping learners realize their responsibility for their own learning and the need to develop their skills required to achieve autonomy. Autonomy may be developed on condition of available opportunities to exercise control over learning. A more student-centered class atmosphere might more easily lead to learner autonomy and help students participate in the social processes of classroom learning actively, to interpret what is new in terms of what has been acquired, and know how to learn and use the knowledge learned in any learning situation at any stage of life. Dickinson and Carver (1980) propose that students themselves need to make preparation to become autonomous language learners and users in three aspects: methodology, psychology, and practice, with ten widely adopted basic techniques for promoting learner autonomy such as self-monitoring, self-correction, group work, extensive reading and listening. Nunan (1997) suggests five with similar levels of learner-centered tasks to help the learners achieve autonomy: awareness, involvement, intervention, creation and transcendence, with implications for the changing roles of learners and teachers in classroom. Awareness refers to students' sensitivity of learning tasks and types of strategies. Involvement indicates that students can be involved more in selection of both tasks and methods. Intervention refers to the teacher's role of facilitator in learning and task negotiator. Creation suggests free decision making in students' tasks. Transcendence is a stage when students control most aspects of their learning and work with 
authentic materials beyond the classroom. The teacher's role changes gradually and flexibly, from a provider of information, stimulator and promoter of students' learning and thinking, to a guide, motivator for students to think creatively, and realistically and to an adviser or monitor. We considered Nunan's sequential model when designing the ELAP, hoping to encourage greater autonomy in our students, which implies better language learning.

The brief review suggests some underlining assumptions that although the concept originated abroad, learner autonomy is a desirable goal to pursue in China's English education since autonomy may be developed through interaction and reflection on proper conditions, and that the ELAP will certainly have an important influence on the development of our students' autonomous learning awareness and ability.

\section{RESEARCh Design AND Methodology}

This is a descriptive study. As has been mentioned above, this research is the microscopic aspect of the macroscopic project JZ0805. Different dimensions of learner autonomy are included, such as motivation, strategy use in out-class English learning and classroom performances followed by perceptions and effect feedback of teachers and students. The ELAP is conducted to better understand how a series of pedagogical activities may affect the development of students' autonomous learning awareness, ability and their English proficiency.

\section{A. Design of the Research}

With an aim to develop learner autonomy, the teachers have designed the ELAP in which students bring their out-class extension learning achievements to class, deliver presentations and share with their classmates in the first 40 minutes of each scheduled 1.5-hour class. The presentations are planned themselves, based on their in-class learning. Following the presentation, the speaker asks 3 to 5 questions to see how well he has made himself understood. Then the teacher and the other students provide feedback and/or ask questions on any aspect of the presentation. Further feedback may be given after class, face to face or through QQ, emails and other means. The students themselves form groups of 3 to 8 , with an elected group leader respectively. Presentation may be delivered together or individually. They may invite any one to help make judgment of the feasibility and value of their topic or draft in preparation. The students should prepare their presentation on the basis of in-class teaching content to make the ELAP more tightly integrated into the overall teaching curriculum.

The overall research is exploratory in nature since the purpose is to summarize and develop a framework of language learner autonomy in which autonomy development and growth of target language proficiency are not only mutually supporting but fully integrated with each other. Considering the young students' characteristics of seeking to do others down, the presentations are graded and marked. And this is an action research, problem-solving in nature since it is conducted to help the puzzled students, who are products of the examination-oriented education, learn how to learn and prepare for lifelong learning.

\section{B. Methodology of the Research}

Both qualitative data and quantitative data are collected from all the classes that the research teachers teach. As has been said above, this research is part of the project. The ELAP is therefore carried out all along and data collection through questionnaires, learning diaries and reports goes with it. The research covers a period from October 2008 to May 2011, during which the junior English majors entered their senior years of university while the senior English majors graduated.

Questionnaires and interviews are designed to have a general knowledge of the students' autonomous learning, motivation and strategy use, while learning reports after the general and course learning orientations are done by all the students based on their learning journals or diaries. Since all the students have finished their learning reports written in accordance with the basic requirements covering belief of English learning, motivation, use of strategies and so on, the data collected can reflect the students' learning condition.

Qualitative data collected from each class are categorized, counted and juxtaposed for further examination. Data collected from the learning reports of all the students and interviews with 10 students from each class are analyzed qualitatively to provide evidence for the development of learner autonomy. Other data resources such as teachers' observation notes of the general classroom atmosphere and students perceptions of the teaching and the ELAP are referred to. All the interviews with the teachers and students are noted down and analyzed qualitatively to identify themes concerning their beliefs and actual practice.

\section{IMPLEMENTATION OF THE ELAP IN CLASS}

The ELAP is conducted in all classes that the research teachers teach for two reasons. One is that the teachers in the team all have realized the significance of establishing learner autonomy, and the other is that the prior surveys of the freshmen as the products of examination-oriented education reveal that they are badly in need of orientation in autonomous learning, The teachers are almost sure that changes will take place. The microscopic orientation and implementation of the ELAP are carried out with the macroscopic and special orientation in the project.

\section{A. Teacher's Orientation of Course Learning}


Orientation of course learning is carried out to give the students a general idea of the basic teaching and learning methods and techniques to help the students realize the urgent demand of learning concept shifts, from teacher-centered to learner-centered, from examination-oriented to quality-oriented, etc.. The students are encouraged to familiarize themselves with the development of economic globalization and its challenge to China's higher education and to have a clear understanding of the $21^{\text {st }}$ century concept-----learning how to learn. And some definitions of learner autonomy are introduced to enable the students to have the awareness of autonomous learning and prepare the ground for them to learn their courses as an autonomous learner does.

\section{B. Teacher's Orientation in the Process of Course Teaching}

Changes need the understanding and commitment of all those affected in the implementation of the project. But it is a practical impossibility to involve everybody in every task. Teachers' assessed skills like previous teaching, knowledge and attitude towards innovation are all important affecting elements in the orientation of learner autonomy, among which attitude is always the key and decision-making power for orientation and student-centered class activities It is essential for the teacher to develop a model of the project from start to finish to orient the students to carry out extension learning outside class. General requirements and directions to conduct ELAP are proposed for students to refer to and commit their energy and certain terms like extension learning are defined to enable them to plan their out class extension learning in advance according to the schedule and content of the course teaching. In teaching, the teacher invites the students to take part in problem-solving activities whenever possible, and encourage them to find more interpretations for a language phenomenon or a person's behavior based on the context, cultural background knowledge to orient them to find paths to the goal themselves.

\section{Presentation in Comprehensive English Class for Junior English Majors}

Presentations delivered by the junior English majors in Comprehensive English class mainly cover 8 aspects relating to the class teaching content, from some interesting phonetic metaphors to the most celebrated festivals, holidays and to the social and historical events, influential figures. Some students have made comparisons of English and Chinese customs and important writers, etc.. All the students have delivered their presentations using PPT. They are so well-prepared that presentation scripts are seldom used though it is right in hand.

During the presentation, the teacher is an enthusiastic participant, keeping natural and encouraging eye contact with the presenter, taking notes while listening. When a speaker finishes his presentation, she leads discussions and seeks feedback. After the students' evaluation, the teacher gives positive comments on the presentation and orients the class to find something to learn from. Warm applause is given to every presenter, an atmosphere of mutual support and cooperation is created. After making general suggestions for improvement on the 4 or 5 planned presentations, the teacher begins her scheduled students-centered teaching, orienting students to observe, analyze, and solve problems themselves. One of the main roles of the teacher at this level is as a motivator for students to think creatively and realistically in classroom teaching orientation.

\section{Presentation in Advanced English Class for Senior English Majors}

Senior English majors concerned in this study have made presentations relating to the content of Advanced English in 9 major aspects, covering social culture in which a specific work was produced, the national, even the international situation of the time, attitudes towards love, work, money, friendship, marriage, etc., critical analysis of American law system, democracy and others. Both PPT and blackboard writing are used in the presentation of the senior English majors. They have done as good a job as the junior English majors. Moreover, they select a student as linkman to host the presentations of the 4 or 5 students each time. The student in charge speaks to make the presentations of the 4 or 5 students an organic whole.

\section{E. Presentation in English Listening and Speaking Class for Junior English Majors}

The junior English majors deliver their presentation in English Listening and Speaking class with a heavy emphasis on the application of basic linguistic and cultural knowledge, and listening strategies and techniques that the teacher has introduced in class. English recordings and authentic materials such as scripts of English film and TV series are used for their analysis of problem-solving process in listening. They have realized the problems in learning and began to do something on purpose, which is shown in their presentation. Topics chosen for the ELAP cover 7 basic areas, from phonetic knowledge such as liaison, elision, weak forms, tones that may affect speaking and listening comprehension, prediction techniques used to guess the general idea of a passage, ending or result, the shift of attitude through topic, words, etc., to cultural differences of English and Chinese that may affect listening comprehension and oral communication.

\section{F. Students'Perceptions of the ELAP and Feedback}

The process of presentation and feedback provide evidence about the ELAP as a whole, in which the students' reflections on out-lass extension learning process in their reports provide insight into the way that emotional factors may influence foreign language learning. According to the data, all the students' autonomous attitudes are positive. In the aspect of motivation to learn English as a foreign language, $100 \%$ of the students say firmly in their reports, journals 
and interviews that with the teacher's orientation, they have been making effort in the learning process and trying to find out how to make progress on the basis of their own reality. Self-confidence as a learner and speaker could be seen in all reports. They feel more confident than before since they have found that they do have the ability to do the presentation well. Willingness to take responsibility for their progress in learning is easily seen and the awareness of teacher independence is revealed. They are eager to demonstrate their own ability to learn. They have managed to make use of the general learning strategies introduced by the teachers in class orientation and those they have learned in extension learning, from the Internet, library, even relatives or friends abroad. The most frequently used strategies mentioned in $100 \%$ of the reports are memory strategies, cognition strategies such as practicing, reading to gather presentation ideas, meta-cognitive strategies like planning their learning; having clear goals, social strategies such as asking others for suggestion, cooperating with others and learning something in the course of helping others. Changes have taken place in the students' autonomous skills and attitudes in the process of ELAP, and insight has been gained concerning the teacher's role and the use of social strategies in the development of learner autonomy in the students.

The students' perceptions of the ELAP and feedback are mainly revealed in their reports, which generally include how they carry out their extension learning and prepare their presentation, what they notice during the preparation and performance stages, their self-evaluation of the performance and the whole process of ELAP. Questionnaires and interviews are also sources for feedback. To a greater or lesser extent, 100\% of the students reflect on their English learning activities inside and outside the classroom. The teachers read all the reports carefully and classify the difficulties that the students have meet, note down the general means that they adopt to solve problems. All the students say that they have tried their best in ELAP and benefited a lot. They have improved their English in trying to realize autonomous learning. Besides good performance in certain examinations and nationwide and provincial English contests mentioned by $30 \%$ of the students, $100 \%$ of the students have expressed their stronger desire for more communication with native English speakers and have tried to create opportunities themselves.

\section{RESEARCH FINDINGS AND DiSCUSSION}

The ELAP results are better than what has been assumed. $100 \%$ of the students have expressed positive attitudes. Besides the variety of knowledge, they mention in their reports that they have been learning how to plan their ELAP, to cooperate with others and learn from others, and that ELAP has enabled them to realize with great joy that they do have the capacity to conduct autonomous learning. They all say that they have been learning to listen to news from VOA, $\mathrm{BBC}$ and other media using strategies and techniques learned in class and benefited a lot. They have realized that many phonetic problems in listening are caused by their inaccurate pronunciation and intonation and inadequate background knowledge and that they will do more work to improve their basic knowledge and comprehensive skills. Over $95 \%$ of them think that they have developed awareness of attempting to obtain both accuracy and fluency in ELAP since well-organized informative materials presented by fluent speakers with good pronunciation and intonation always attract more attention, win a bigger round of applause and have better evaluation, And 100\% of them say that in order to do better ELAP, they have tried to make full use of the learning resources available, invite others to help with their rehearsals for improvement.

In evaluation, about $100 \%$ of the students mainly acknowledge the achievements of the others' presentation and only touch the weakness slightly since they think that everybody has tried his/her best and has something to be learned from. However, they express the shades of meanings in the use of words and phrases such as wonderful, excellent, marvelous, extraordinary, very good, good, ok, etc.. Although they all say that they would appreciate feedback on ELAP, it seems that they prefer after-class exchange of opinions in terms of weakness and shortcomings, partly because of time limit and partly for face-saving factor. Only about $40 \%$ of the students give both positive and negative feedback to others' ELAP, and the rest only provide the positive.

The teachers are greatly encouraged. They get some enlightenment about both the difficulties and problems that the students have mentioned and what they are interested in, which may guarantee a more definite objective in specific teaching and orientation. Moreover, changes have taken place in the students' learning concept and methods. They are highly motivated, no longer puzzled by the shifts of environments, although there are still challenges of interdisciplinary knowledge accumulation, all kinds of examinations and so on.

The results reveal that belief in learning through production activities does have played an important role in ELAP. ELAP gives students opportunities to use language as the whole process is one of the common student-centered experiential learning techniques (Brown, 2001: 224). Experiential learning can foster the students' willingness and ability to create personal learning contexts, which is essential to the development of learner autonomy (Littlewood, 1996). Therefore, getting students to learn through activities like ELAP helps developing learner autonomy.

It is also demonstrates that students can only be truly motivated if they really want to achieve something themselves. They will always be eager to look out for opportunities to develop skills in using learning strategies, plan their study and reflect immediately after all the ELAPs. Peer feedback given right afterwards orally or in written form through email, etc. seems to be more encouraging than marks. The warm applause after every presentation is a great spiritual support and an atmosphere of cooperation has been created, which in turn has boosted the morale. Since creativity is advocated from the very beginning of ELAP, all the students have managed to display something attractive or instructive. And they all say in their reports that they do have improved their English comprehensively as they have 
always been trying to learn creatively.

\section{CONCLUSION}

To verify the assumption that the students' autonomous learning ability may be developed, this study, as a microscopic aspect of learner autonomy orientation project, is conducted to explore the impact of ELAP on the development of learner autonomy. As a result, $100 \%$ of the students concerned give positive evaluation, in the process of which they have realized both the development of English language proficiency and autonomous learning. The study demonstrates that the concept of learner autonomy does fit for eastern culture as well as it does for the west culture if the students are given appropriate orientation. And the teacher does play an instrumental role in helping the learners how to learn (Ellis and Sinclair, 1987, p167). However, for limitations of space, the authors' academic knowledge and others, detailed description of the ELAP is not provided here. And moreover, great perseverance shown in the face of difficulties is, and will always be an important guarantee for the success of establishing learner autonomy on both the teachers' and the students' sides since some protracted and potential effect for lifelong learning needs further examination.

\section{REFERENCES}

[1] Benson, P. (2001). Teaching and Researching Autonomy in Language Learning. Hong Kong: Longman.

[2] Benson, P. (2005). Teaching and Researching Autonomy in Language Learning. Beijing: Foreign Language Teaching and Research Press.

[3] Brown, J. D. (2001). Understanding Research in Second Language Learning. Beijing: Foreign Language Teaching and Research Press, the People's Education Press \& Cambridge University Press.

[4] Dam, L. (1994). How Do We Recognize an Autonomous Classroom?. Die Neuere Sprache,

[5] Dam, L. (1995). Learner Autonomy: From Theory to Classroom Practice. Dublin: Authentik.

[6] Dickinson, L. and D. (1980). Carver. Learning How to Learn: Steps towards Self-direction in Foreign Language Learning. ELT Journal.

[7] Dickinson, L. (1995). Autonomy and Motivation: a Literature Review. System.

[8] Ellis, G. and B. Sinclair. (1987). Helping Learners Discover Their Learning Styles. In R. Duda, and P. Riley. (Eds.). Learning Style. Nancy: Presses Universitaires de Nancy.

[9] He, Lian-zhen. (2003). Learner Autonomy and Its Development. Foreign Language Teaching and Research.

[10] Holec, H. (1981). Autonomy in Foreign Language Learning. Oxford: Pergamon Press.

[11] Lamb, T. E. \& H. Reinders (eds,). (2007). Learner and Teacher Autonomy: Concepts, Realities and Responses. Amsterdam: John Benjamins.

[12] Little, D. (1991). Learner Autonomy 1: Definitions, Issues and Problems. Dublin: Authentik.

[13] Little, D. (2002). The European Language Portfolio: Structure, Origins, Implementation and Challenges. Language Teaching.

[14] Littlewood, W. (2001). Students' Attitudes to Classroom English Learning: a Cross-cultural Study. Language Teaching Research.

[15] Liu, Zhen-qian.(2004). Problems and Solutions in Foreign Language Education in China. Shandong Foreign Language Teaching Journal.

[16] Nunan, D. (1997). Designing and Adapting Materials to Encourage Learner Autonomy. P. Benson, \& P. Voller (eds.). Autonomy and Independence in Language Learning. London: Longman.

[17] Van Kees, E. and Oliver St. J. (2003). A Framework for Freedom: Learner Autonomy in Foreign Language Teacher Education. New York Peter Lang Publishing, Incorporated.

[18] Wenden, A. (1991). Helping Language Learners Think about Learning. ELT Journal.

[19] Williams, M., \& Burden, R. (2006). Psychology for Language Teachers. Beijing: Foreign Language Teaching and Research Press, the People's Education Press \& Cambridge University Press.

Haiyan Liu was born in Weifang, China in 1969. She received her MA degree in linguistics from Shandong University, China in 2007.

She is currently an associate professor in the School of Foreign Languages, University of Jinan, China. Her research interests include applied linguistics and language teaching.

Wenqian Qi was born in Weifang, China. She is currently an English teacher in the School of Foreign Languages, Shandong University of Finance and Economics, China. Her research interests include applied linguistics and language teaching. 